\title{
Inadequate Device Immunity
}

National Cancer Institute

\section{Source}

National Cancer Institute. Inadequate Device Immunity. NCI Thesaurus. Code C92135.

Problems related to immunity or capabilities to resist electromagnetic interference (EMI). 